\title{
Involvement of thromboxane and leukotriene in arachidonate induced coronary constriction in diabetic rats
}

\author{
Y.Takiguchi, K. Umemura, H.Hashimoto and M. Nakashima \\ Department of Pharmacology, Hamamatsu University School of Medicine, Hamamatsu, Japan
}

\begin{abstract}
Summary. Vascular responsiveness to sodium arachidonate was examined in isolated perfused hearts from rats with streptozotocin-induced diabetes. In diabetic rats arachidonate induced a biphasic coronary vascular response characterized by initial vasoconstriction followed by prolonged vasodilation. Non-diabetic rats showed only a vasodilator response. The vasoconstrictor phase found in diabetic rats was abolished by $\mathrm{ONO}-3708$, a selective thromboxane $\mathrm{A}_{2}$ antagonist. Indomethacin partly inhibited the vasoconstrictor response, the residual response being abolished by a leukotriene antagonist,
\end{abstract}

ONO-1078. The vasodilator response, however, was completely abolished by indomethacin in both diabetic and nondiabetic rats. Furthermore, the coronary constrictor response to leukotriene $\mathrm{D}_{4}$ was enhanced in diabetic compared to nondiabetic rats. These results suggest an involvement of leukotriene in the vasoconstrictor response to arachidonate in diabetic rats, especially when cyclooxygenase is inhibited.

Key words: Leukotriene, thromboxane $\mathrm{A}_{2}$, arachidonic acid, vasoconstriction, coronary artery, diabetic rats.
Arachidonic acid (AA) is metabolized by two enzyme systems (cyclooxygenase and lipoxygenases), forming prostaglandins (PGs), thromboxanes (TXs), leukotrienes (LTs) and other compounds [1]. The LTs, $\mathrm{LTC}_{4}$ and $\mathrm{LTD}_{4}$, have been shown to induce profound coronary vasoconstriction $[2,3]$. The release of an LT-like substance from porcine coronary arteries after challenge with the calcium ionophore A23187 has been reported [4]. Recently, Piomelli et al. [5] showed that canine and human coronary vessels metabolized exogenous AA to $\mathrm{LTC}_{4}$ and $\mathrm{LTD}_{4}$.

Coronary heart disease is the major cause of death among diabetic patients [6]. Metabolites of AA may be involved in the alteration of coronary vascular function in diabetes. Studies comparing diabetic and normal animals showed either decreased [7-9] or increased [7, 10, 11] PG production of AA metabolites in blood vessels of diabetic animals. Gimeno et al. [12] suggested an involvement of lipoxygenase products in AA-evoked constriction of coronary arteries from diabetic dogs.

We investigated the involvement of $\mathrm{LTC}_{4}$ and $\mathrm{LTD}_{4}$ in the altered vascular reactivity to $\mathrm{AA}$ in diabetic rats. We examined the effects of selective TXA 2 and LT antagonists on the vascular responses of isolated perfused hearts from rats with streptozotocin-induced diabetes.

\section{Materials and methods}

\section{Experimental animals}

Diabetes was induced in male Wistar rats (weight $230-250 \mathrm{~g}$ ) by i.v. injection of streptozotocin $(35 \mathrm{mg} / \mathrm{kg}$ dissolved in citrate buffer at $\mathrm{pH}$ 4.5). The animals were used 10 weeks later. Diabetic rats markedly lost body weight $(190 \pm 3.4 \mathrm{~g}, n=32)$ as compared to age-matched normal rats $(301 \pm 19 \mathrm{~g}, n=6)$. Therefore weight-matched $(192 \pm 4.3 \mathrm{~g}$, $n=17$ ), non-diabetic rats, obtained by restricting food intake, were used as controls.

A further group of animals was obtained by treating 5 of the diabetic rats with insulin, $4 \mathrm{U}$ regular Insulin Lente (Novo, Bagsvaerd, Denmark) administered s.c. daily for 3 weeks, starting 7 weeks after the streptozotocin injection.

Blood collected when the rats were killed, was used for glucose determination by the o-toluidin boric acid method using a glucose test kit (Wako, Tokyo, Japan). The blood glucose level was significantly elevated in the diabetic group $(30.8 \pm 0.6 \mathrm{mmol} / 1, n=32, p<0.01)$ as compared to the control group $(9.9 \pm 0.3 \mathrm{mmol} / 1, n=17)$. The diabetic, insulin-treated rats had also normal blood glucose levels $(10.1 \pm 0.2 \mathrm{mmol} / 1, n=5)$ and their body weights were also normal $(303 \pm 8.3 \mathrm{~g}, n=5)$.

\section{Perfused heart preparation}

Hearts were quickly excised under anaesthesia with sodium pentobarbital ( $30 \mathrm{mg} / \mathrm{kg}$, i.v.). All hearts were perfused by the Langendorff technique. A constant aortic pressure of $80 \mathrm{~mm} \mathrm{Hg}$ was used for an 
$A$

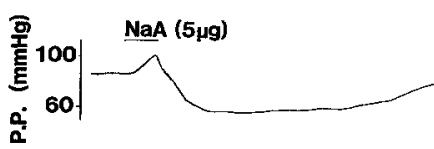

$B$

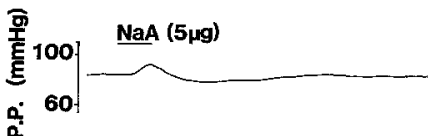

$c$

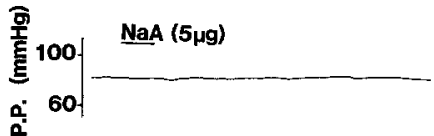

Control rats

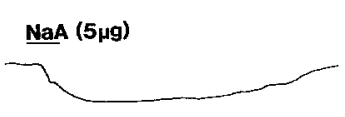

NaA (5 5 g)

Fig. 1. Typical tracings of the responses to sodium arachidonate $(\mathrm{NaA})$ of isolated perfused hearts from diabetic and control rats (A), effects of indomethacin (B) and BW755C (C). NaA $(5 \mu \mathrm{g})$ was infused for $1 \mathrm{~min}$. Indomethacin $(5 \mu \mathrm{mol} / 1)$ and BW755C $(10 \mu \mathrm{mol} / 1)$ were applied $15 \mathrm{~min}$ before NaA infusion. PP: perfusion pressure

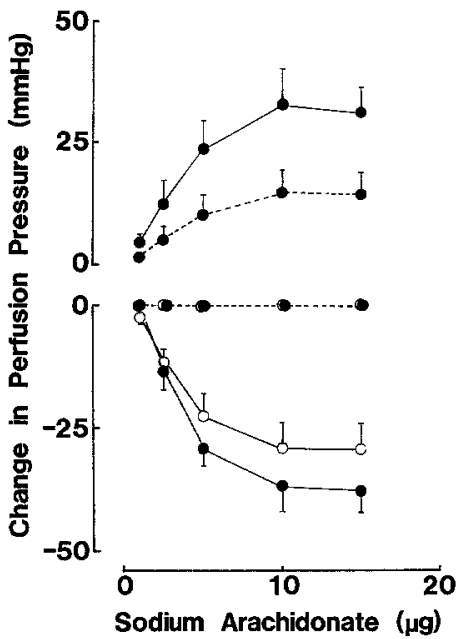

Fig. 2. Effects of indomethacin on arachidonate-induced vasoconstriction (upper panel) and vasodilation (lower panel) in isolated perfused hearts from diabetic $(O)$ and control $(O)$ rats. Solid and dotted lines represent the response to arachidonate before and after treatment with indomethacin $(5 \mu \mathrm{mol} / \mathrm{l})$, respectively. Indomethacin was applied $15 \mathrm{~min}$ before arachidonate infusion. Values are shown as mean \pm SEM $(n=7)$
$\boldsymbol{A}$
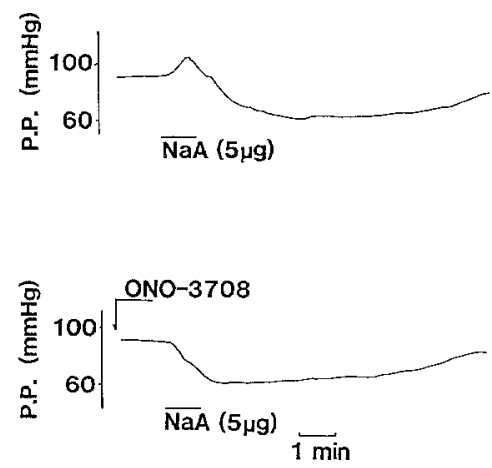

B

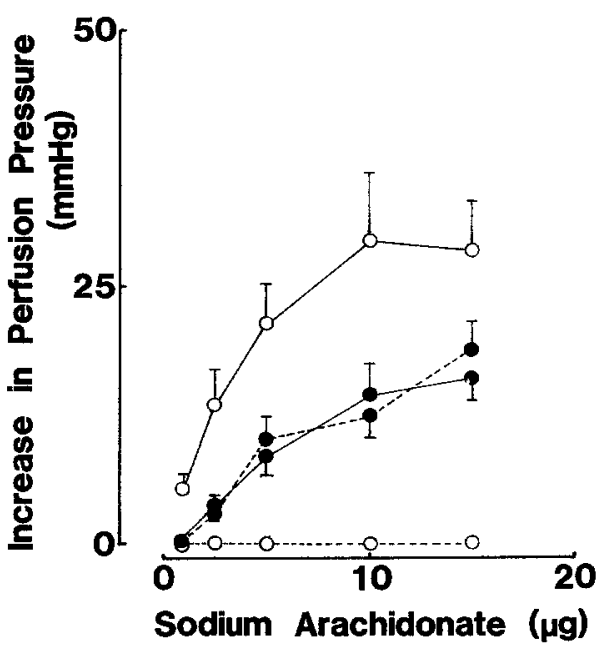

Fig.3. Effects of ONO-3708 on arachidonate-induced vasoconstriction in isolated perfused hearts from diabetic rats. (A) Typical tracings of the response to sodium arachidonate $(\mathrm{NaA})$ $(5 \mu \mathrm{g})$ before and after treatment with ONO-3708 $(0.5 \mu \mathrm{mol} / 1)$. PP: perfusion pressure. (B) Dose-response curves for $\mathrm{NaA}$-induced vasoconstriction in the absence $(O)$ and presence $(O)$ of indomethacin $(5 \mu \mathrm{mol} / \mathrm{l})$. Solid and dotted lines represent the response to $\mathrm{NaA}$ before and after treatment with ONO$3708(0.5 \mu \mathrm{mol} / 1)$, respectively. ONO3708 or/and indomethacin was administered $15 \mathrm{~min}$ before $\mathrm{NaA}$ infusion. Values represent mean $\pm \operatorname{SEM}(n=5)$ initial $10 \mathrm{~min}$, then the perfusion was switched to a constant flow of $12 \mathrm{ml} / \mathrm{min}$. The perfusate employed was Krebs-Ringer solution aerated with a mixture of $95 \% \mathrm{O}_{2}$ plus $5 \% \mathrm{CO}_{2}$ and maintained at $37^{\circ} \mathrm{C}$ (Taiyo, Tokyo, Japan). The Krebs-Ringer solution contained $\mathrm{NaCl} 120, \mathrm{KCl} 4.7, \mathrm{CaCl}_{2} 2.0, \mathrm{KH}_{2} \mathrm{PO}_{4} 1.2, \mathrm{NaHCO}_{3} 25.0, \mathrm{MgSO}_{4} 1.2$ and glucose $14.0(\mathrm{mmol} / \mathrm{l})$. Coronary perfusion pressure was monitored from a side-arm in the aortic inflow tract, connected to a pressure transducer (Nihon-Kohden, MPU-0.5, AP621G, Tokyo, Japan) and recorded on a thermal array recorder (Nihon-Kohden, WS-681G, Tokyo, Japan).

\section{Experimental protocol and drugs}

After an equilibration period of $30 \mathrm{~min}$, sodium arachidonate (NaA) was infused into the perfusate in a volume of $100 \mu \mathrm{l}$ for $1 \mathrm{~min}$. PGs and LT analogues were injected as boluses in a volume of 3-5 $\mu 1$. Dose-response curves were performed non-cumulatively while ventricular fibrillation was induced and maintained by electrical stimulation. In order to assess antagonist and inhibitor effects, these drugs were added $15 \mathrm{~min}$ prior to the $\mathrm{NaA}$ injections and they were kept in the perfusate continuously throughout each experiment.

The following drugs were used: sodium arachidonate, indomethacin, leukotriene $D_{4}$, prostaglandin $E_{2}$, prostaglandin $I_{2}$ and streptozotocin (Sigma Chemical Co., St. Louis, Mo, USA); 9,11-epithio-11,12-methano-thromboxane $\mathrm{A}_{2}$ (STA $)$, ONO-1078 (4-oxo-8-(p-
(4-phenylbutyloxy)benzoylamino)-2-(tetrazol-5-yl)-4H-1-benzopyran hemihydrate) and ONO-3708 $((9,11),(11,12)$-dideoxy- $9 \alpha, 11 \alpha$-dimethylmethano-11,12-methano-13,14-dihydro-13-aza-14-oxo-15-cy clopentyl-16,17,18,19,20-pentanor-15-epi-thromboxane $A_{2}$ ) (Ono Pharmaceutical Co, Osaka, Japan). BW755C was synthesized in our laboratory.

\section{Statistical analysis}

Results are expressed as mean \pm SEM. Statistical evaluation was performed by Student's $t$-test and differences were considered significant for $p<0.05$.

\section{Results}

\section{Differing effects of NaA on diabetic and control rats}

Basal perfusion pressure of diabetic rat hearts $(84.3 \pm 1.9 \mathrm{~mm} \mathrm{Hg}, n=32)$ was not significantly different, from that of control rat hearts $(80.2 \pm 1.9 \mathrm{~mm} \mathrm{Hg}$, $n=17)$. Typical records of the responses of perfusion pressure to exogenous $\mathrm{NaA}$ are shown in Figure 1. 
$\mathrm{NaA}$ induced a biphasic coronary response characterized by initial vasoconstriction followed by prolonged vasodilation in diabetic rat hearts. Hearts from control rats showed only vasodilation in response to $\mathrm{NaA}$. The dilator response to $\mathrm{NaA}$ was comparable in both groups (Fig.2). The cyclooxygenase inhibitor indomethacin $(5 \mu \mathrm{mol} / 1)$, completely abolished the vasodilator response in both diabetic and control rats. However, the vasoconstrictor phase observed in diabetic rats was only partly blunted by indomethacin. BW755C $(10 \mu \mathrm{mol} / 1)$ which inhibits both cyclooxygenase and lipoxygenase, completely abolished both phases of the vascular response to $\mathrm{NaA}$ observed in diabetic animals (Fig. 1).

\section{Effects of $T X A_{2}$ and LT antagonists on the contractile response to $\mathrm{NaA}$ in diabetic rats}

Diabetic, but not control, rats showed a dose-dependent coronary constriction induced by $\mathrm{NaA}$ (Fig.3). The vasoconstrictor phase was abolished by ONO-3708 $(0.5 \mu \mathrm{mol} / 1)$, a selective TXA 2 antagonist [13], while the vasodilator phase was not affected. The residual vasoconstriction produced by $\mathrm{NaA}$ in the presence of indomethacin $(5 \mu \mathrm{mol} / 1)$ was, however, not inhibited by ONO-3708.

ONO-1078 (1 $\mu \mathrm{mol} / 1)$, a selective antagonist of $\mathrm{LTC}_{4}$ and $\mathrm{LTD}_{4}$ [14], did not alter the vasoconstricting effect of $\mathrm{NaA}$ in the absence of indomethacin. However, the residual vasoconstriction produced by $\mathrm{NaA}$ in the presence of indomethacin was inhibited by ONO1078 (Fig.4).

\section{Effects of $L_{T D}, T X A_{2}, P G I_{2}$ and $P G E_{2}$}

Dose-response curves to $\mathrm{LTD}_{4}, \mathrm{STA}_{2}$, a stable $\mathrm{TXA}_{2}$ analogue [15], $\mathrm{PGI}_{2}$, and $\mathrm{PGE}_{2}$ are shown in Figure 5. The vasoconstrictor response to $\mathrm{LTD}_{4}$ was significantly increased in diabetic animals compared with that of the control animals $(p<0.05)$. There were no significant differences between diabetic and control rats in vascular reactivity to $\mathrm{STA}_{2}, \mathrm{PGI}_{2}$ and $\mathrm{PGE}_{2}$, indicating that the increased responsiveness to $\mathrm{LTD}_{4}$ was specific.

The responses to $\mathrm{STA}_{2}$ and $\mathrm{LTD}_{4}$ were selectively inhibited by ONO-3708 $(0.5 \mu \mathrm{mol} / 1)$ and ONO-1078 (1 $\mu \mathrm{mol} / 1)$, respectively, in the two groups (not shown).

\section{Effect of insulin treatment}

In insulin-treated diabetic rats the vasoconstrictor phase was not observed and as with the hearts of control rats, only vasodilation was seen (Fig. 6). Treatment with insulin thus reversed the altered response to $\mathrm{NaA}$ found in diabetic rats.

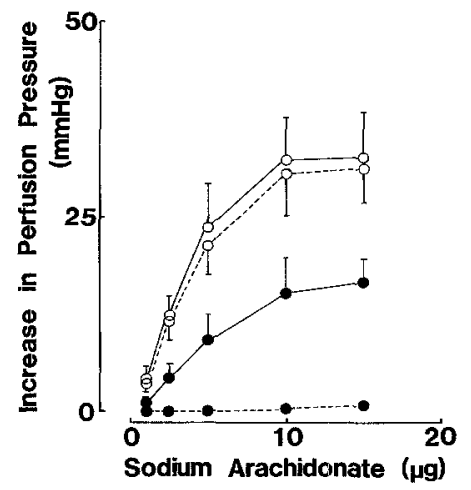

Fig.4. Effects of ONO-1078 on arachidonate-induced vasoconstriction in the absence $(O)$ and presence $(O)$ of indomethacin ( 5 umol/l) in isolated perfused hearts from diabetic rats. Solid and dotted lines represent the response to sodium arachidonate $(\mathrm{NaA})$ before and after treatment with $\mathrm{ONO}-1078$

( $1 \mu \mathrm{mol} / 1)$, respectively. ONO 1078 was administered 15 min before $\mathrm{NaA}$ infusion. Values represent mean $\pm \operatorname{SEM}(n=7)$

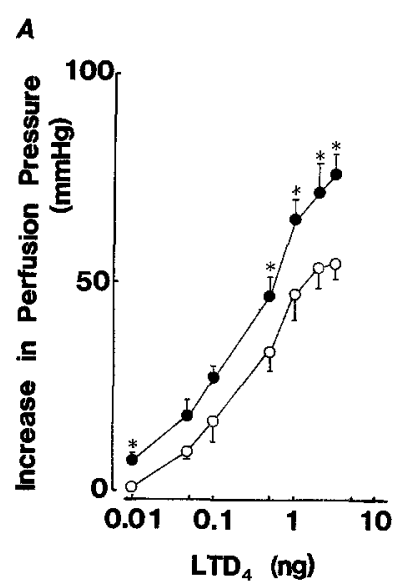

$\boldsymbol{B}$
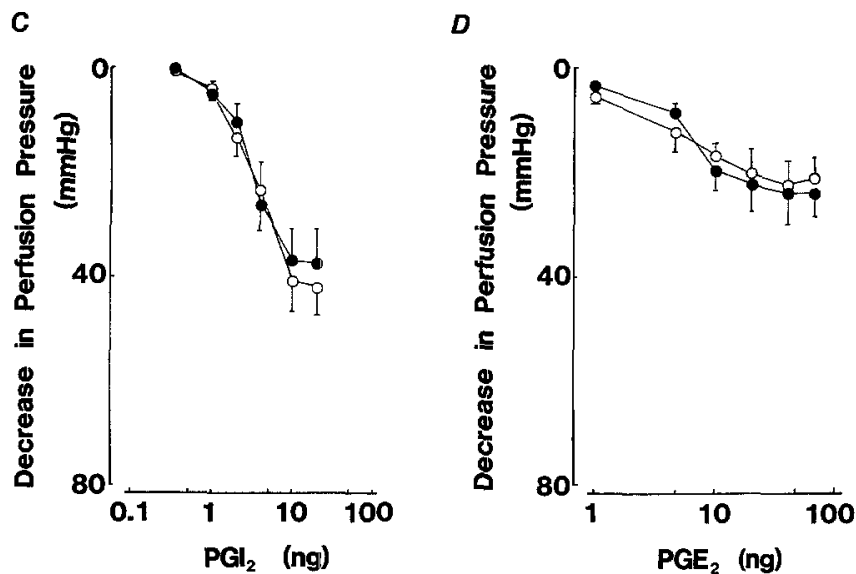

Fig.5. Dose-response curves for (A) leukotriene $D_{4}$, (B) stable thromboxane $\mathrm{A}_{2}$ analogue $\left(\mathrm{STA}_{2}\right)$, (C) prostaglandin $\mathrm{I}_{2}$ and (D) prostaglandin $\mathrm{E}_{2}$ in isolated perfused hearts from diabetic (O) and control $(O)$ rats. Values represent mean $\pm \operatorname{SEM}(n=5)$. Asterisks indicate significant difference from control rats $(p<0.05)$

\section{Discussion}

It is well established that the administration of AA into the coronary circulation is followed by an increased formation of PGs [16]. $\mathrm{PGI}_{2}$ has been found to be the major metabolite of AA in the heart [17]. However, several investigators have reported an altered metabolism of vascular AA in diabetes mellitus [7-11]. In the present study, exogenous $\mathrm{NaA}$ produced coronary dilatation in non-diabetic rats. In contrast, untreated diabetic 


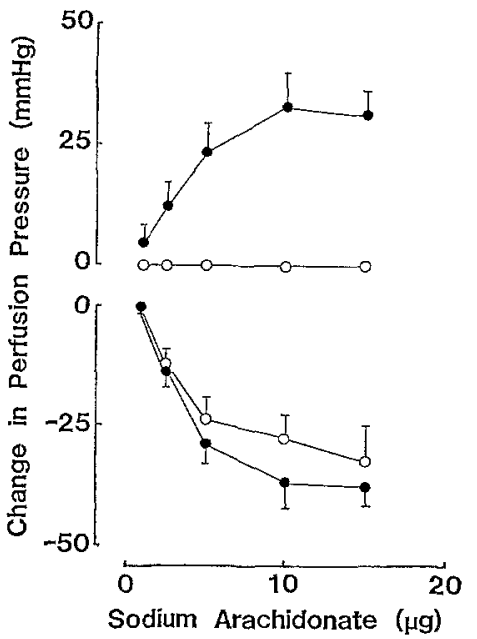

Fig. 6. Effect of insulin treatment on the altered response to arachidonate in isolated perfused hearts from diabetic rats. Upper panel: vasoconstrictor phase. Lower panel: vasodilator phase. 9 , non-treated diabetic rats $(n=7) ; 0$, insulin-treated diabetic rats $(n=5)$. Values represent mean \pm SEM

rats responded to $\mathrm{NaA}$ administration with a biphasic coronary response, characterized by an initial vasoconstriction followed by a slowly developing and long-lasting vasodilation. Again, only the vasodilator response to $\mathrm{NaA}$ was obtained in insulin-treated diabetic rats.

The initial vasoconstriction phase found in the diabetic rats was abolished by a selective $\mathrm{TXA}_{2}$ antagonist, ONO-3708 [13]. ONO-3708 had little effect on vascular responses to other PGs and $\mathrm{LTD}_{4}$. These results indicate that $\mathrm{TXA}_{2}$ may be responsible for the vasoconstriction by $\mathrm{NaA}$ in diabetic animals. According to the results of Roth et al. [7], aortic rings of diabetic rats showed an increased responsiveness to carbocyclic $\mathrm{TXA}_{2}$. However, the constrictor response to $\mathrm{STA}_{2}$, a stable $\mathrm{TXA}_{2}$-analogue, was not enhanced in coronary vessels of isolated perfused hearts from diabetic rats. This difference might indicate that vessels of different anatomical origin might be affected differently by the diabetic condition. Our findings indicate that coronary constriction by $\mathrm{NaA}$ in diabetic animals may be the result of increased $\mathrm{TXA}_{2}$ generation in the vessels.

Indomethacin partly inhibited the vasoconstriction produced by $\mathrm{NaA}$, while $\mathrm{BW} 755 \mathrm{C}$, which inhibits both cyclooxygenase and lipoxygenase(s) activities abolished the vasoconstriction. Similarly Gimeno et al. [12] showed that NaA-evoked constriction of coronary artery strips from diabetic dogs was abolished by the lipoxygenase inhibitor nordihydroguaiaretic acid but not by indomethacin and salicylic acid, compounds which act at the cyclooxygenase level. Therefore, we investigated the potential participation of lipoxygenase products in NaA-evoked constriction of coronary arteries in diabetic rat hearts.

The 5-lipoxygenase products $\mathrm{LTC}_{4}$ and $\mathrm{LTD}_{4}$ have been found to constrict coronary arteries $[2,18,19]$. Recently, Piomelli et al. [5] showed that canine and human coronary vessels metabolized exogenous AA to $\mathrm{LTC}_{4}$ and $\mathrm{LTD}_{4}$. Therefore, we wondered whether $\mathrm{LTC}_{4}$ and $\mathrm{LTD}_{4}$ might participate in the vasoconstrictor effect of $\mathrm{NaA}$ in diabetic rats. We used ONO-1078, a newly synthesized selective antagonist of $\mathrm{LTC}_{4}$ and $\mathrm{LTD}_{4}$ [14] to address this problem. The vasoconstriction produced by $\mathrm{NaA}$ in the presence of indomethacin was eliminated by ONO-1078, but not by ONO-3708, which suggested that LTs may play a role as a mediator of coronary constriction in diabetes when cyclooxygenase is inhibited. However, ONO-1078 did not affect the vasoconstrictive effect of $\mathrm{NaA}$ in the absence of indomethacin. Therefore, LTs may not be implicated in NaAevoked constriction as long as the cyclooxygenase pathway is intact. This is also supported by the observation that the $\mathrm{TXA}_{2}$ antagonist completely abolished the vasoconstrictor response under these conditions. However, the vascular responsiveness to $\mathrm{LTD}_{4}$ was enhanced in the perfused hearts from diabetic animals. Therefore, the NaA-evoked coronary constriction seen in the presence of indomethacin appears to result from increases in both the generation of, and vascular reactivity to, LTs. The involvement of lipoxygenaseproduct, perhaps LTs, in NaA-evoked coronary constriction in diabetic dogs has been reported even in the absence of indomethacin [12]. In this species LTs appear to assume an even more prominent constrictor role under diabetic conditions.

The vasodilator response to $\mathrm{NaA}$ was not altered under diabetic conditions. Indomethacin completely abolished the vasodilation in both groups. Furthermore, there were no differences between the groups with respect to the vascular responses to prostanoid vasodilators (i.e. $\mathrm{PGI}_{2}$ and $\mathrm{PGE}_{2}$ ).

In conclusion, NaA-evoked coronary constriction found in diabetic rats was mediated by TXA 2 . However, when cyclooxygenase activity was inhibited, vasoconstriction still occurred, the LTs being responsible. This response may partly be attributed to increased vascular responsiveness to LTs in diabetic animals. Our results indicate that, in addition to $\mathrm{TXA}_{2}$, LTs may play a role in the altered response to AA in diabetes. These findings may have clinically important implications for diabetic patients treated with non-steroidal, anti-inflammatory drugs such as indomethacin. Further investigation into production of PGs and LTs is needed to clarify the causes of the altered AA response. It is possible that the alterations in vascular response to AA may be related to coronary artery dysfunction which is frequently found in patients with diabetes mellitus.

Acknowledgements. STA 2 , ONO-3708 and ONO-1078 were kindly provided by Ono Pharmaceutical Company, Osaka, Japan. This work was supported in part by Grant-in-Aid for Encouragement of Young Scientists from the Ministry of Education, Science and Culture, Japan (No.63772016).

\section{References}

1. Moncada S, Vane JR (1978) Unstable metabolites of arachidonic acid and their role in haemostatis and thrombosis. Br Med Bull 34: $129-135$

2. Burke JA, Levi R, Guo Z-G, Corey EJ (1982) Leukotrienes $C_{4}, D_{4}$ and $E_{4}$ : effects of human and guinea-pig cardiac preparations in vitro. J Pharmacol Exp Ther 221: 235-241 
3. Piper PJ (1984) Formation and actions of leukotrienes. Physiol Rev 64: 744-761

4. Piper PJ, Letts LG, Galton SA (1983) Generation of leukotrienelike substance from porcine vascular and other tissues. Prostaglandins 25: 591-599

5. Piomelli D, Feinmark SJ, Cannon PJ (1987) Leukotriene biosynthesis by canine and human coronary arteries. $\mathbf{J}$ Pharmacol Exp Ther 241: 763 -770

6. West KM (1978) Epidemiology of diabetes and its vascular lesions. Elsevier, New York

7. Roth DM, Reibel DK, Lefer AM (1983) Vascular responsiveness and eicosanoid production in diabetic rats. Diabetologia 24: 372-376

8. Harrison HE, Reece AH, Johnson M (1978) Decreased vascular prostacyclin in experimental diabetes. Life Sci 23: 351-356

9. Rogers SP, Larkins RG (1981) Production of 6-oxo-prostaglandin $F_{1} \alpha$ by rat aorta; Influence of diabetes, insulin treatment, and caloric derivation. Diabetes 30: 935-939

10. Rösen P, Schrör K (1980) Increased prostacyclin release from perfused hearts of acutely diabetic rats. Diabetologia 18: 391-394

11. Sterin-Borda L, Borda ES, Gimeno MF, Lazzari MA, Del Castillo E, Gimeno AL (1982) Contractile activity and prostacyclin generation in isolated coronary arteries from diabetic dogs. Diabetologia 22: $56-59$

12. Gimeno AL, Sterin-Borda L, Del Castillo EJ, Gimeno MF (1983) Arachidonate evokes constriction of coronary and mesenteric arteries isolated from diabetic dogs. Adv Prostaglandin Thromboxane Leukotriene Res 12: 235-240

13. Fujioka M, Nagao T, Kuriyama $H$ (1986) Actions of the novel thromboxane $\mathrm{A}_{2}$ antagonists, ONO-1270 and ONO-3708, on smooth muscle cells of the guinea-pig basilar artery. NaunynSchmiederberg's Arch Pharmacol 334: 468-474
14. Obata T, Katsube N, Miyamoto $T$, Toda $M$, Okegawa $T$, Nakai H, Kosuge S, Konno M, Arai Y, Kawasaki A (1985) New antagonists of leukotrienes: ONO-RS-411 and ONO-RS-347. Adv Prostaglandin Thromboxane Leukotriene Res 15: 229-231

15. Katsura M, Miyamoto T, Hamanaka N, Kondo K, Terada T, Ohgaki Y, Kawasaki A, Tsuboshima M (1983) In vitro and in vivo effects of new powerful thromboxane antagonists (3-alkylamino pinane derivatives). Adv Prostaglandin Thromboxane Leukotriene Res 11: 351-357

16. Needleman $P$ (1978) Experimental criteria for evaluating prostaglandin biosynthesis and intrinsic function. Biochem Pharmacol 27: $1515-1518$

17. De Decker EAM, Nugteren DH, Ten Hoor F (1977) Prostacyclin is the major prostaglandin released from the isolated perfused rabbit and rat heart. Nature 268: 160-163

18. Letts LG, Newman DL, Greenwald SE, Piper PJ (1983) Effects of intra-coronary administration of leukotriene $\mathrm{D}_{4}$ in the anesthetized dog. Prostaglandins 26:563-572

19. Roth DM, Lefer AM (1983) Studies on the mechanism of leukotriene induced coronary artery constriction. Prostaglandins 26: $573-581$

Received: 10 November 1988

and in revised form: 4 April 1989

Dr. M. Nakashima

Department of Pharmacology

Hamamatsu University School of Medicine

Hamamatsu 431-31

Japan 